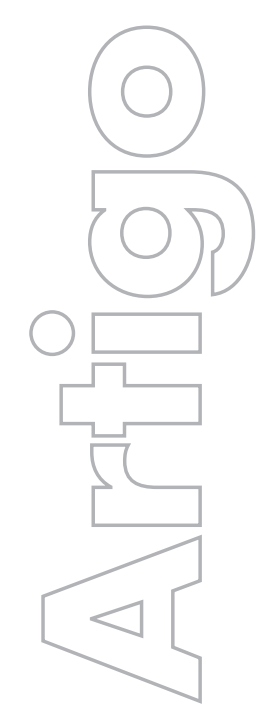

revista

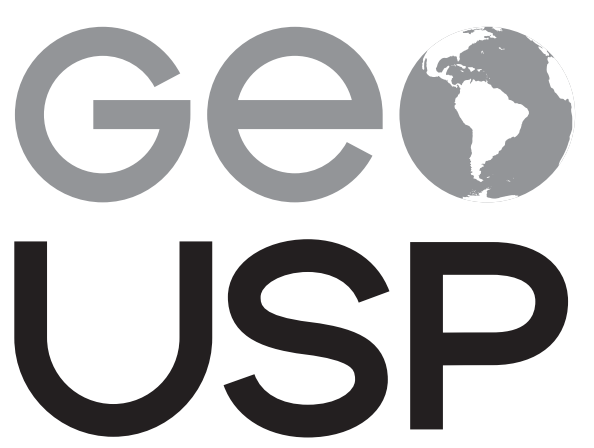

espaço e tempo

Volume $23 \cdot n^{\circ} 2$ (2019)
Planejamento corporativo do território brasileiro: contribuição geográfica à análise crítica da concessão aeroportuária

\author{
Adriana Maria Bernardes Silva \\ Universidade Estadual de Campinas - Brasil
}

Sérgio Henrique de Oliveira Teixeira Instituto Federal de Educação, Ciência e Tecnologia do Sul de Minas Gerais - Brasil

p. $242-261$

Como citar este artigo:

SILVA, A. M. B.; TEIXEIRA, S. H. O. Planejamento corporativo do território brasileiro: contribuição geográfica à análise crítica da concessão aeroportuária. Geousp - Espaço e Tempo (Online), v. 23, n. 2, p. 242-261, ago. 2019. ISSN 2179-0892.

Disponível em: https://www.revistas.usp.br/geousp/article/ view/156773. doi: https://doi.org/10.11606/issn.2179-0892. geousp.2019.156773.

\section{(c) (1) (8)}

Este artigo está licenciado sob a Creative Commons Attribution 4.0 License. 


\title{
Planejamento corporativo do território brasileiro: contribuição geográfica à análise crítica da concessão aeroportuária ${ }^{1}$
}

\section{Resumo}

Este artigo busca contribuir para a análise do processo de privatizações e concessões das infraestruturas compostas dos sistemas de engenharia territoriais, desencadeado no Brasil a partir da década de 1990. Analisamos, em particular, as três primeiras rodadas de concessão dos aeroportos administrados pela empresa estatal Infraero (que tiveram início em 2011). Defendemos que, para além da ideologia do planejamento estratégico, verifica-se o fortalecimento de um planejamento corporativo a partir do controle da materialidade (aeroportos) e dos fluxos (linhas/malhas) por corporações nacionais e internacionais, como empreiteiras, fundos de investimento e consultorias. Constatamos que o controle dos fluxos e dos fixos dota as grandes corporações de um poder articulador do território, imprimindo-lhe uma lógica extravertida e globalizante que cada vez mais coloca o Estado como apêndice do planejamento feito pelas empresas.

Palavras-chave: Planejamento corporativo. Uso corporativo. Concessão aeroportuária. Espoliação territorial. Corporações.

\section{Corporate planning of Brazilian territory: geographical contribution to the critical analysis of the airport concession}

\begin{abstract}
This article aims to contribute to the analysis of the processes of privatization and concessions of the infrastructures composed of the territorial engineering systems that have occurred in Brazil since the 1990's. We analyze, in particular, the first
\end{abstract}

1 Este artigo contou com o apoio do Conselho Nacional de Desenvolvimento Científico e Tecnológico (CNPq)/Edital Universal - 453914/2014-4. Vigência do projeto: 2014-2018. 
three rounds of concession of the airports, administered by the state company Infraero (which began in 2012). We argue that, beyond the strategic planning ideology, there is a strengthening of corporate planning coming from the control of materiality (airports) and flows (lines/meshes) by national and international corporations such as contractors, investment funds and consultancies. We find that the control of flows and fixed assets endow the large corporations with an articulating power of the territory, imprinting on this an extraverted and globalizing logic that increasingly places the State as an appendage of the planning done by the companies.

Keywords: Corporate planning. Corporate use. Airport concession. Territorial spoliation. Corporations.

\section{Planific ación corporativa del territorio brasileño: contribución geográfica al análisis crítico de la concesión aeroportuaria}

\section{Resumen}

Este artículo tiene como objetivo contribuir al análisis del proceso de privatizaciones y concesiones de las infraestructuras compuestas por los sistemas de ingeniería territorial, ocurridas en Brasil a partir de la década de 1990. En este artículo analizamos, en particular, las tres primeras rondas de concesiones de los aeropuertos administrados por la empresa estatal Infraero (que iniciaron en 2012). Defendemos que, además de la ideología de la planificación estratégica, se verifica el fortalecimiento de una planificación corporativa a partir del control de la materialidad (aeropuertos) y de los flujos (líneas/malla) por corporaciones nacionales e internacionales, así como contratistas, fondos de inversión y consultorías. Constatamos que el control de los fluxos y de los fijos dan a las gran corporaciones un poder articulador del territorio, imprimiendo en este una lógica extravertida y globalizante que pone cada vez más el Estado como un apéndice de la planificación hecha por las empresas.

Palabras clave: Planificación corporativa. Uso corporativo. Concesión de aeropuertos. Expoliación territorial. Corporaciones. 


\section{Introdução}

À medida que a fluidez territorial se torna cada vez mais imprescindível para manter o ritmo da acumulação, as corporações largam os contextos da globalização nas formações socioespaciais (Santos, 2005), ${ }^{2}$ impondo lógicas de constrangimento ao Estado. Estabelecem um domínio direto e indireto dos sistemas de engenharia de fluxos e possibilitam a dinamização de novas interações espaciais no território (Corrêa, 2006). A recente concessão do sistema de engenharia aeroportuário brasileiro encontra-se no limiar desse processo, que vimos denominando uso corporativo do território (Santos, 1993, 1994).

Compõem o uso corporativo do território a relação fundamental entre o controle dos fixos e fluxos que articulam o território (envolvendo as rodovias, os aeroportos, portos, entre outros) e o controle dos círculos de cooperação no espaço (Santos, 1996; Santos; Silveira, 2001; Silva, 2002) estabelecidos por empresas globais de informação (envolvendo empresas de consultoria, fundos de pensão, escritórios de advocacia, seguradoras, agências de rating, agências de marketing e publicidade, entre outras). $\bigcirc$ caso em tela desse artigo busca elucidar como as corporações, por meio do controle das materialidades fixas e dos fluxos territoriais, passaram a influir vigorosamente no planejamento territorial brasileiro nas últimas décadas. Trata-se de um processo de espoliação (Harvey, 2005) por meio do uso corporativo das infraestruturas territoriais estatais, iniciada na década de 1990 com as privatizações e aprofundado nas décadas de 2000 e 2010 com as concessões.

Objetivamos, portanto, problematizar a lógica corporativa global da acumulação via espoliação (Harvey, 2004) presente no Plano Nacional de Desestatização (PND) desde a década de 1990. Identificamos três elementos que, sob o ponto de vista da análise geográfica, demonstram o processo de uso corporativo do território: (i) a utilização dos fundos públicos para financiamento da espoliação, (ii) a participação de grandes empresas globais de consultoria no controle dos processos gerenciais e na elaboração do diagnóstico das infraestruturas territoriais e (iii) o desdobramento da maior participação das corporações na dinâmica dos fixos e dos fluxos territoriais, influindo, portanto, no planejamento territorial.

A importância das concessões aeroportuárias para entender o processo de espoliação em curso é destacada por terem sido os aeroportos os maiores sistemas de engenharia territoriais inclusos no PND por meio de concessões. ${ }^{3}$

Conforme a Tabela 1, observa-se que o PND entre 1990 e 2015 obteve a receita de cerca de U\$ 54 bilhões. A concessão dos seis primeiros aeroportos (valor absoluto) representa (conforme o universo abaixo) 43\% do total obtido em toda o PND, excetuando a concessão de hidrelétricas.

2 Propomos, como Santos (1977), interpretar o território circunscrito à nação por meio da categoria formação socioespacial. Trata-se de entender a categoria espaço a partir da proposição marxista de formação econômica e social (FES) como categoria adequada para a formulação de uma teoria do espaço, definida como "a evolução diferencial das sociedades, no seu quadro próprio e em relação com as forças externas de onde mais frequentemente lhes provém o impulso" (Santos, 2005 p. 22).

3 Tal fato causou controvérsias na análise geográfica e científica pelas disputas de seus significados: estaríamos vivendo uma privatização clássica aos moldes neoliberais da década de 1990 ou o processo de concessão seria algo novo? Ainda que relevante, não procuramos neste trabalho levantar essa questão como mote de nossa pesquisa. Nossa contribuição, entretanto, busca elucidar como as concessões têm imprimido um uso do território cada vez mais corporativo. 
Tabela 1 - Receita por setor do PND no período 1990-2015, em U\$ (milhões)*

\begin{tabular}{|l|l|l|l|l|l|}
\hline setor & $\begin{array}{l}\text { número de } \\
\text { desestatizações }\end{array}$ & $\begin{array}{l}\text { receita } \\
\text { de venda }\end{array}$ & setor & $\begin{array}{l}\text { número de } \\
\text { desestatizações }\end{array}$ & $\begin{array}{l}\text { receita } \\
\text { de venda }\end{array}$ \\
\hline aeroportuário & 6 & $23.430,21$ & petroquímica & 27 & $2.698,50$ \\
\hline siderurgia & 8 & $5.561,50$ & ferroviário & 7 & $1.696,90$ \\
\hline mineração & 2 & $5.201,80$ & outros & 6 & 623,89 \\
\hline petróleo e gás & 1 & $4.840,30$ & portuário & 7 & 420,80 \\
\hline financeiro & 6 & $4.515,10$ & fertilizantes & 5 & 418,20 \\
\hline energia elétrica & 3 & $3.908,20$ & rodoviário** & 21 & 0,00 \\
\hline total & & & & 99 & $54.542,43$ \\
\hline
\end{tabular}

fonte: BNDES (2016).

\begin{abstract}
* A tabela não contempla o resultado referente à outorga de concessões de aproveitamento hidrelétrico e linhas de transmissão.

** Os leilões para concessão das rodovias federais foram por menor tarifa, sem pagamento de bônus de outorga ao governo.
\end{abstract}

Nesse sentido, observando a magnitude e a importância do sistema de engenharia aeroviário, buscamos contribuir com o debate sobre a natureza da espoliação territorial ${ }^{4}$ brasileira identificando a lógica de uso corporativo do território.

\title{
Aeroportos, concessões e planejamento corporativo
}

A importância da movimentação no território (de pessoas, mercadorias, informações e capital) está ancorada no aprofundamento da divisão territorial do trabalho a partir da década de 1970. A mundialização e a reestruturação da produção global (Chesnais, 1996) fragmentou e especializou as diversas fases do processo produtivo em diversos espaços nacionais.

Para Harvey (1992), Antunes (1999) e Lojkine (1995), entre outros, a reestruturação produtiva dá origem a um regime de acumulação flexível. ${ }^{5} \bigcirc$ capital passa a se utilizar da flexibilidade na produção nos mais diversos âmbitos, seja na flexibilização dos direitos trabalhistas, seja na flexibilização da produção em distintas regiões do mundo. Segundo Santos (1996) e Santos e Silveira (2001), essa fragmentação da produção leva a estruturação de circuitos espaciais produtivos de alcance global que são dependentes de sistemas de engenharia (fixos) e de sistemas de fluxos (materiais ou imateriais) para seu eficaz funcionamento. Tais sistemas de engenharia respondem pela solidariedade geográfica entre os lugares (Santos, 1996; Contel, 2001) e são fundamentais, por conseguinte, nas estratégias de planejamento territorial em suas diversas escalas.

O sistema de engenharia aeroportuário, em especial, destaca-se por ser responsável pela fluidez de alta velocidade e de grandes distâncias, tendo assim um papel relevante na integração de um país de dimensões continentais como o Brasil.

4 Entendemos as privatizações e concessões como uma espoliação territorial. Trata-se de identificar o processo de espoliação, tal como definido por Harvey (2005), aplicado às infraestruturas territoriais.

5 "A acumulação flexível envolve rápidas mudanças nos padrões de desenvolvimento desigual, tanto entre setores como entre regiões geográficas, criando, por exemplo, um vasto movimento no emprego no chamado setor de serviços, bem como conjuntos industriais totalmente novos em regiões até então subdesenvolvidas" (Harvey, 1992, p. 140). 
A concessão desse sistema deve ser problematizada e analisada minuciosamente, uma vez que o seu controle dota as corporações de enorme capacidade de intervenção na rede urbana e nos espaços regionais. Nesse sentido, poder-se-ia admitir que há, hoje, uma terceirização do planejamento e da gestão do território brasileiro que passa, em grande medida, para as corporações internacionais.

É importante destacar que o processo de construção, manutenção e ampliação do sistema de aeroportos, os (fixos aeroportuários) e suas conexões (fluxos e interações espaciais), se consolidou historicamente sob a administração do Estado - nas várias escalas da federação - sustentando o período de investimentos públicos em sistemas de infraestrutura. A Empresa Brasileira de Infraestrutura Aeroportuária (Infraero) nasce nesse contexto (em 1972) como empresa estatal pública responsável por operar a organização do sistema de aeroportos. Desde então, se consolidou como operadora aeroportuária de grande eficiência, organizando uma rede que, até o começo de sua concessão, iniciada em 2011, contava com um total de 67 aeroportos distribuídos por todo o território, responsável por $97 \%$ de todo o transporte aéreo de passageiros e 99\% do total de transporte aéreo de carga no território (Infraero, 2016b).

A estratégia do sistema aeroviário ampliou a possibilidade de ocupar e integrar o território nacional ${ }^{6}$ nas últimas décadas, como se vê na Figura l e no Mapa 1.

\section{Figura 1 - Evolução do fluxo de passageiros no Brasil - 1972-2010}
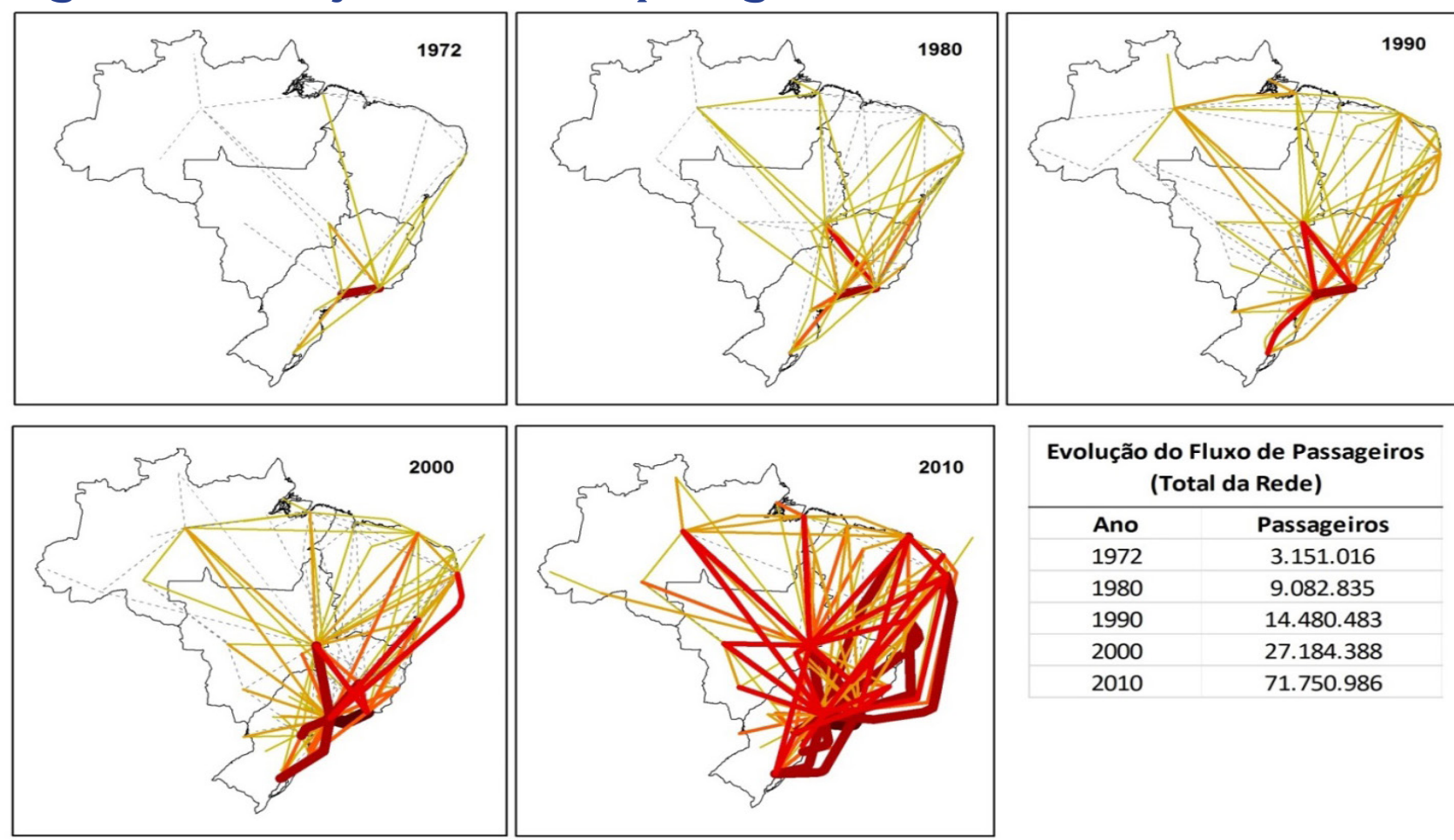

Evolução do Fluxo de Passageiros (Total da Rede)

Fonte: Fonte: Anuário do transporte aéreo 1980. Brasilia, DF: Agência Nacional de Aviação Civil - ANAC, [1981]. Até 1974, publicado sob o título Anuário Estatístico da Aviação Civil. Até 2004, publicado sob a responsabilidade do Departamento de Aviação Civil - DAC, Rio de Janeiro. Disponivel em: <http://www.anac.gov. br/estatistica/estatisticas1.asp >. Acesso em: abr. 2013.

fonte: Anac (1972-2010); IBGE (2013).

elaboração: Os autores.

6 Utilizamos como série histórica para manter o padrão de dados a periodização e a base de dados fornecida pela Agência Nacional de Aviação Civil (Anac) em seus anuários estatísticos, publicados desde 1972, por conta da organização sistêmica dos dados pela administração da Infraero. Somamos à organização dos dados as bases territoriais e de ligações aéreas fornecidas pelo estudo Redes e fluxos no território: ligações aéreas 2010, publicado pelo Instituto Brasileiro de Geografia e Estatística (IBGE) em 2013. 


\section{Mapa 1 - Ligações aéreas de passageiros - 2010}

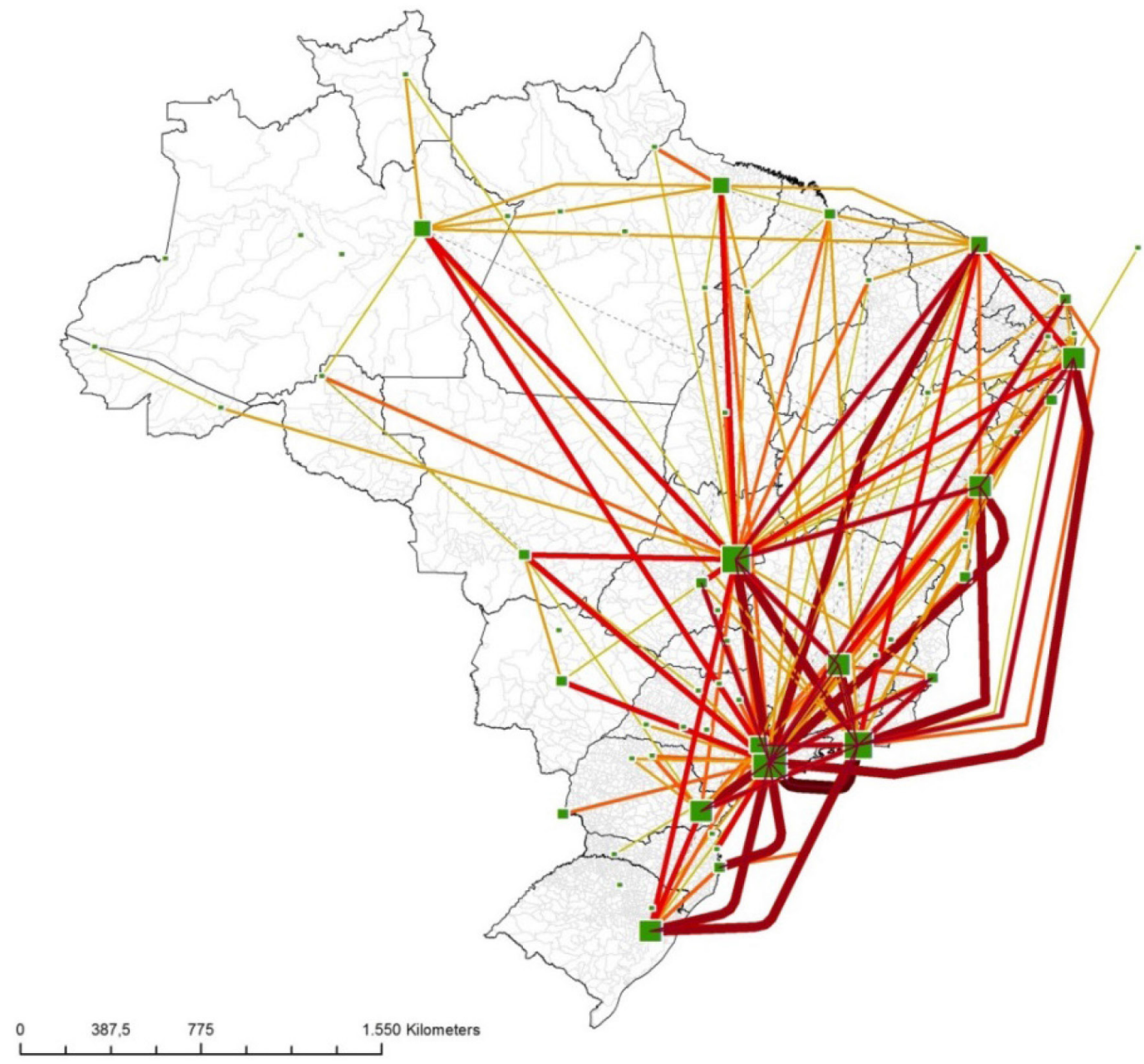

\section{Fluxo de Passageiros Cidade (x 1000) \\ - até 1000 \\ - 1000 a 2500 \\ - 2500 a 5000 \\ 5000 a 10000 \\ 10000 a 17095}

ageiros

fonte: Anac (1972-2010); IBGE (2013).

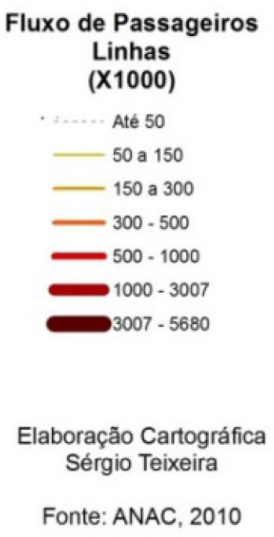

Os dados acima demonstram que houve crescimento dos fluxos de passageiros no sistema aeroviário a partir da década de 1970. Em 1972, o fluxo na rede registrava cerca de 3 milhões de passageiros transportados, já em 2010 o número de passageiros transportados passa dos 70 milhões. Esse vertiginoso crescimento do fluxo foi acompanhado por um adensamento de aeroportos e de malhas de fluxos correspondentes, consolidando uma rede nacional relativamente dispersa.

Ao relacionar a malha de fluxos com suas densidades nas principais cidades posicionadas como centros de gestão no território (Corrêa, 1996; IBGE, 2008), constatamos que o padrão topológico da rede revela, ainda, uma malha adensada na Região Concentrada, ${ }^{7}$ envolvendo as principais cidades das regiões Sul e Sudeste. Conforma-se, portanto, um sistema de interligação territorial

7 A denominação Região Concentrada foi introduzida na literatura geográfica com as pesquisas dirigidas por Milton Santos e Ana Clara Torres Ribeiro em 1979. Essa região é constituída pelos estados do Rio de Janeiro, do Espírito Santo, de Minas Gerais, de São Paulo, do Paraná, de Santa Catarina e do Rio Grande do Sul e por áreas do CentroOeste. Sua gênese se deve aos acréscimos de uma base técnica ao território provenientes da economia cafeeira e, posteriormente, da industrialização e do investimento do Estado em infraestruturas para as empresas, destacadamente na região circunvizinha a São Paulo. Superpõe-se, hoje, um sistema de objetos técnicos informacionais. A densidade demográfica, por sua vez, impulsiona também a divisão do trabalho e a especialização dessas áreas, que concentram cada vez mais incrementos materiais e imateriais à produção globalizada. 
com sentido predominante para a região de maior aporte de técnica e informação. $\bigcirc$ modal aeroviário torna-se, como bem apontaram Cordeiro e Ladeira (1988), ${ }^{8}$ uma das principais linhas de interligação de mercadorias de alto valor agregado e de transporte de altos executivos, intensificando as interações espaciais (Corrêa, 2006) entre as cidades polarizadoras da rede urbana.

Entretanto, quando observada a organização da infraestrutura dos aeroportos, nota-se que estes não são equipados com a demanda necessitada pelos fluxos. À medida que crescem os fluxos de passageiros também crescem os números de aeronaves com portes e tecnologias mais modernas o que, por sua vez, demanda o aumento de pistas, a operação de novos terminais de passageiro, novos pátios de estacionamento, entre outras adequações. Há um desencaixe entre fixos e fluxos, manifesto na limitação de infraestrutura dos aeroportos.

A necessidade de investimentos em infraestrutura aeroportuária, dada sua importância para a interligação territorial, foi anunciada ano a ano por meio dos relatórios estatísticos da Infraero. Entretanto, o Estado brasileiro, em consonância com a lógica espoliativa global, passou a requisitar estudos que demonstrassem novas saídas para os investimentos em fixos aeroportuários. Conforme analisado por Teixeira (2018a), estudos relacionados à operação aeroportuária foram, então, produzidos pela Anac, Comando Aeronáutico e Banco Nacional de Desenvolvimento Econômico e Social (BNDES).

\section{Quadro 1 - Estudos sobre a privatização dos aeroportos no Brasil}

\begin{tabular}{|l|l|l|}
\hline ano & estudo & objetivo \\
\hline 2003 & $\begin{array}{l}\text { Aeroportos e Privatizações: pro- } \\
\text { posta de privatização aeroportuária } \\
\text { para o Brasil (Comando da Aero- } \\
\text { náutica) }\end{array}$ & $\begin{array}{l}\text { Informar sobre o desenvolvimento do processo de pri- } \\
\text { vatização aeroportuária e sugerir opções de concessão } \\
\text { que possam se adequar ao modelo de administração de } \\
\text { aeroportos adotado no Brasil }\end{array}$ \\
\hline 2008 & $\begin{array}{l}\text { Relatório de desempenho regulató- } \\
\text { rio } 2008 \text { (Anac) }\end{array}$ & $\begin{array}{l}\text { Elaboração de medidas para retirar restrições não ope- } \\
\text { racionais em aeroportos centrais; a criação de regra de } \\
\text { entrada em aeroportos com limitação de novos voos; a } \\
\text { liberação das tarifas internacionais; e a preparação de } \\
\text { um marco regulatório para a concessão dos aeroportos } \\
\text { brasileiros à iniciativa privada }\end{array}$ \\
\hline 2008 & $\begin{array}{l}\text { Projetos do setor de transporte } \\
\text { Aéreo e Concessão de Aeroportos } \\
\text { (BNDES) }\end{array}$ & $\begin{array}{l}\text { O estudo busca legitimar as futuras intervenções do } \\
\text { BNDES no processo de privatizações operado como } \\
\text { concessão }\end{array}$ \\
\hline \multirow{2}{*}{2009} & $\begin{array}{l}\text { Estudo econômico sobre regulação } \\
\text { e concorrência do setor de aero- } \\
\text { portos (Anac) }\end{array}$ & $\begin{array}{l}\text { Traça uma revisão completa da privatização e pela } \\
\text { primeira vez adota o conceito de concessão como o } \\
\text { melhor modelo para o Brasil }\end{array}$ \\
\hline $\begin{array}{l}\text { Relatório Consolidado de Estudo } \\
\text { do Setor de Transporte Aéreo do } \\
\text { Brasil (McKinsey E Company) }\end{array}$ & $\begin{array}{l}\text { A realização de uma avaliação técnica para o desenvol- } \\
\text { vimento e a modernização da Aviação Civil Brasileira, } \\
\text { servindo de base política e institucional para o processo } \\
\text { de concessão dos principais aeroportos do Brasil. }\end{array}$ \\
\hline
\end{tabular}

fontes: Anac (2008); BNDES (2008); Fiúza e Pioner (2009); Kapp (2003).

8 "Assim, fortaleceu-se sobremaneira a acessibilidade do transporte aéreo no circuito intermetropolitano que já se firma no período anterior: essencial à circulação dos profissionais das atividades da economia transnacional, esses fluxos proporcionaram e impuseram a onipresença das metrópoles, sobretudo as das regiões-core sobre a rede urbana das regiões periféricas" (Cordeiro; Ladeira, 1988, p. 293). 
Tais estudos, sistematizados no Quadro 1, indicam uma série de diretrizes, entre elas, a recomendação de parcerias público-privadas (PPP) e concessões, ambas como instrumentos estratégicos para alavancar e concretizar os macroinvestimentos demandados. $\bigcirc$ ápice desse processo ocorre com a contratação da consultoria global McKinsey $\varepsilon$ Company pelo BNDES para também propor diretrizes ao setor.

A contratação da consultoria supracitada não se faz por mero acaso. Desde a década de 1990, conforme destaca Silva e Farias (2008), Silva e Manzoni Neto (2008), Silva (2009) e Teixeira e Silva (2011), Teixeira (2018b), essas empresas têm participado ativamente dos processos de privatização e concessões no Brasil.

\section{Nas asas da privatização: as concessões dos aeroportos no Brasil e a me- diação da consultora McKinsey E Company}

As privatizações e as concessões fazem parte do processo de reestruturação corporativa que abrange várias escalas territoriais e mudanças no ordenamento empresarial. Para reorganizar a produção e as ações do Estado, as empresas globais de consultoria em estratégia são requisitadas a cumprir função de diagnosticar o território e, consequentemente, passam também a incorporar o papel de planejar o território (Silva, 2001, 2009). Podemos dizer que a terceirização do planejamento às consultoras marca o início do planejamento corporativo do território (Teixeira, 2018b).

Identificadas como portadoras das lógicas extravertidas da globalização na formação socioespacial brasileira (Silva, 2001), as consultoras globais guardam em seus bancos de dados informações estratégicas à reestruturação do território e ao processo de espoliação. Propomos, aqui, uma interpretação das atividades desenvolvidas pela empresa de consultoria McKinsey E Company no processo de espoliação por meio das concessões dos aeroportos brasileiros.

A McKinsey E Company nasceu em 1926 nos EUA e, desde então, se consolidou como uma das maiores empresas de consultoria em negócios corporativos do mundo. A consultora atua na área de consultoria estratégica há 90 anos, conta com 120 escritórios em cerca de 60 países e uma renda anual que chegou a U\$ 8,8 bilhões em 2016 (McKinsey E Company, 2016). Entre os clientes, encontram-se, segundo a revista Forbes, dois terços das maiores corporações mundiais (McKinsey E Company, 2018). Ressalta-se que, por terem relações corporativas de alto nível nos círculos de cooperação entre as empresas, a consultora passa a se articular em uma lógica espacial de comando, instalando seus escritórios nos principais centros de gestão do território dos países onde atuam. ${ }^{9}$

O poder dessa empresa e sua relação com o Estado brasileiro na condução do planejamento da política econômica é sabido e amplamente divulgado. A rede de consultores da McKinsey E Company atuou nos últimos anos como articuladora de projetos de distintos governos. Evidencia-se, portanto, a relevância no debate feito por Santos (1998), segundo o qual

9 No Brasil, a empresa conta com quatro escritórios: dois na cidade de São Paulo (SP), um na cidade do Rio de Janeiro (RJ) e um na cidade de Salvador (BA). Essas são cidades do mais alto nível da hierarquia de comando na rede urbana brasileira (IBGE, 2014). 
assistimos ao avanço da política feita pelas empresas, sobretudo pelas de maior porte. Tanto a base material dos lugares quanto as ações organizativas tendem cada vez mais a se subordinarem ao seleto grupo de empresas globais de informações, como no caso aqui analisado da consultoria estratégica. Silva (2009, p. 10), destaca o poder articulador dessas empresas que guardam em seus serviços os ideários da globalização e desenham o escopo das empresas e do Estado: "[...] as grandes organizações desenharam suas políticas territoriais valendo-se de modelos de gestão difundidos mundialmente por novos atores sociais, especialmente os vinculados ao ideário da ordem global".

Assim, diante da necessidade imposta pelos impulsos corporativos de reorganizar o setor aeroportuário de acordo com os modelos de gestão internacionais, o Estado brasileiro, por meio do BNDES, contratou a consultora McKinsey \& Company para desenvolver um estudo ${ }^{10}$ que pudesse nortear o planejamento da rede de aeroportos no Brasil.

O estudo intitulado Relatório Consolidado de Estudo do Setor de Transporte Aéreo do Brasil (McKinsey E Company, 2010) visava fazer uma avaliação técnica para o desenvolvimento e a modernização da aviação civil brasileira, servindo de base técnica, política e institucional para o processo de concessão dos principais aeroportos do Brasil. A McKinsey $\varepsilon$ Company contou com a colaboração do Instituto Tecnológico da Aeronáutica (ITA) e da Fundação Instituto de Pesquisa Econômica (Fipe) para legitimar seu caráter técnico e científico; no entanto, uma análise apurada mostra que a questão política foi privilegiada, dada a decisão de entregar o setor à iniciativa privada.

A análise do relatório em tela nos permitiu constatar alguns problemas. Destacamos, em primeiro lugar, que o estudo considerou apenas os 20 principais aeroportos do país, o que prejudica uma análise sistêmica, já que o setor envolvia uma rede estatal sob comando da Infraero que contava com 67 aeroportos. Em segundo lugar, apontamos a desconsideração do estudo sobre o fato de que o sistema aéreo brasileiro trabalha em rede por meio de subsídios cruzados. A rede de fluxos de passageiros, como vimos, encontra maior densidade na Região Concentrada do território e, dessa maneira, os aeroportos situados nessa região acabam por receber a maior parte das receitas, sendo os que operam com lucro. Os aeroportos que não são lucrativos recebem subsídios provenientes dos mais lucrativos, mantendo, assim, a rede funcionando. Assim a consultora tece uma avaliação compartimentada da rede. Em terceiro lugar, mas não menos importante, tem-se o fato de a consultora ter apoiado as diretrizes do relatório nos interesses de determinados agentes corporativos ${ }^{11}$ que contribuíram para definir o modus operandi do projeto: A-Port, Invepar, AG Concessões, Aeropuertos de México (Advent), Aéroport de Paris (AdP). Para se ter uma ideia do perfil destas empresas, organizamos o Quadro 2.

$10 \bigcirc$ estudo fez parte do termo de cooperação técnica firmado entre o Ministério da Defesa (MD) e a Anac para reorganizar a estrutura aeroportuária no Brasil.

11 Entre os demais agentes ouvidos pela McKinsey \& Company, estão órgãos do Governo Federal ligados ao setor aeroportuário, companhias aéreas e entidades patronais de classe (McKinsey \& Company, 2010, p. 43). 


\section{Quadro 2 - Operadores e investidores em infraestrutura ouvidos pela McKinsey E Company para organizar o Relatório Consolidado de Estudo do Setor de Transporte Aéreo do Brasil (McKinsey E Company, 2010)}

\begin{tabular}{|c|c|}
\hline $\begin{array}{l}\text { grupo de } \\
\text { operação e } \\
\text { investimento }\end{array}$ & constituição e atuação \\
\hline A-Port & $\begin{array}{l}\text { Grupo constituído pelo Grupo Camargo Corrêa (Brasil), Flughafen Zürich AG (Suíça) } \\
\text { e Gestión e Ingeniería SA-IDC (Chile). Segundo dados da Infraero (2016b), excluindo } \\
\text { o aeroporto de Zurich, os demais aeroportos operados pelo grupo são de pequeno por- } \\
\text { te. Ressalta-se, ainda, que um dos participantes é o grupo Camargo Corrêa, empreitei- } \\
\text { ra de grande porte que tem se inserido nas recentes concessões em outros setores. }\end{array}$ \\
\hline Invepar & $\begin{array}{l}\text { Constituída pela Previ, Petros, Funcef e OAS. } \bigcirc \text { grupo de fundos de investimento não } \\
\text { tinha, na época do relatório, nenhum tipo de investimento em aeroportos; no entanto, } \\
\text { sabe-se que esses fundos de pensão estão totalmente ligados à lógica dos investimen- } \\
\text { tos em setores concedidos ou privatizados ao capital. Já a construtora OAS, à época } \\
\text { do relatório, não tinha nenhum investimento em aeroportos; no entanto, a consulta à } \\
\text { empresa parece não ter sido casual, já que hoje a OAS é responsável pela construção } \\
\text { de terminais no aeroporto de Guarulhos e do aeroporto Zumbi dos Palmares, em Ala- } \\
\text { goas. Cumpre, ainda, ressaltar que o consórcio foi um dos participantes no leilão que } \\
\text { arrematou os aeroportos de Guarulhos, Viracopos e Brasilia. }\end{array}$ \\
\hline AG Concessões & $\begin{array}{l}\text { Grupo encabeçado pela construtora Andrade Gutierrez, que também não tem ex- } \\
\text { periência em operação de aeroportos; recentemente, associou-se aos grupos Aecon } \\
\text { (Canadá), Airport Development Corporation (Canadá) e Houston Airport System } \\
\text { (EUA) para construir e operar o novo aeroporto de Quito (Equador) e o Aeroporto } \\
\text { Aeris (Costa Rica). A AG Concessões é hoje uma das principais participantes nos pro- } \\
\text { jetos de concessões das rodovias brasileiras. Dessa maneira, a consulta a essa empresa } \\
\text { também estaria vinculada à sua eventual participação nos processos de concessões } \\
\text { dos aeroportos. }\end{array}$ \\
\hline $\begin{array}{l}\text { Advent Interna- } \\
\text { tional }\end{array}$ & $\begin{array}{l}\text { Associada no Brasil à Odebrecht no negócio de aeroportos, explora serviços de } \\
\text { alimentação em aeroportos (no Brasil, já tem grande presença em alimentação e free } \\
\text { shops), opera apenas aeroportos de pequeno porte, à exceção de Santo Domingo, na } \\
\text { República Dominicana, e tem em construção um terminal de passageiros no aeroporto } \\
\text { da cidade do México. }\end{array}$ \\
\hline AdP & $\begin{array}{l}\text { AdP de Paris é responsável pela administração dos dois principais aeroportos de Paris } \\
\text { (Paris-Orly e Paris-Charles-de-Gaulle). Há mais de cinco anos esses aeroportos en- } \\
\text { frentam problemas de má gestão com constantes greves de trabalhadores que reivindi- } \\
\text { cam melhores condições de trabalho e melhoras nos serviços aos usuários. }\end{array}$ \\
\hline
\end{tabular}

fontes: Duclos (2013); McKinsey \& Company (2016); Invepar ([s.d.]); Andrade Gutierrez ([s.d.]); Advent International ([s.d.]); Groupe ADP ([s.d.]); Exame ([s.d.]. organização: Sérgio Teixeira, 2018.

A análise do quadro coloca em questão a mediação pretensamente neutra do relatório. Ao estabelecer como interlocutoras as empresas que participaram e arremataram os aeroportos, a consultora favorece as empresas e corporações em detrimento dos interesses dos órgãos estatais e da sociedade brasileira. 
Tomadas como meta as diretrizes do relatório da McKinsey E Company, coube ao Estado também operar no campo da política de financiamento a efetivação da espoliação do setor aeroportuário. Assim como foi no caso das privatizações do PND na década de 1990, as concessões terão como aporte recursos dos cofres públicos por meio do financiamento e apoio do BNDES.

\section{Uso dos fundos públicos e controle territorial por corporações: articula- ções entre Estado e empresas}

O PND ${ }^{12}$ é a maior expressão da espoliação da infraestrutura territorial em curso desde a década de 1990, pois se trata da substituição do projeto de desenvolvimento nacional em benefício de um projeto de inserção competitiva nos mercados internacionais, a partir das privatizações. Tal programa faz parte de uma série de transformações que indicam a mudança de período que se inicia, posto que o Estado se retira de setores estratégicos que passam a ser administrados por grandes corporações, todavia, valendo-se dos usos dos fundos públicos.

U uso dos fundos públicos para a criação das empresas estatais e para sua posterior privatização encontram maior expressão, por sua vez, na utilização das receitas do BNDES. A criação do BNDES (em 1952, ainda sob o nome de BNDE) se deu pela política estatal de expansão dos sistemas de engenharia no território. Conforme assinala Vainer (2007), foram os grandes projetos de investimento (GPI) que estruturaram os sistemas de energia, transporte, mineração, entre outros, com o objetivo de avançar na integração nacional para a industrialização. Nesse período, as estratégias nacionais desenvolvimentistas buscavam dinamizar a industrialização brasileira e o banco serviria a tal projeto.

A partir do final da década de 1980, houve um aprofundamento das transformações do papel do banco, que passou a ser colocado para gerenciar os planos de privatizações no Brasil; contraditoriamente, passou a agir desestruturando o sistema que ajudou a construir. $\bigcirc$ papel do BNDES nas privatizações foi fundamental para estabelecer uma participação ainda maior do Estado no processo de espoliação territorial, pois foi o banco responsável por gerenciar os leilões e fornecer linhas de crédito às empresas para os investimentos nas estatais a serem privatizadas (Silva; Farias, 2008). Em suma, tratou-se de assumir os riscos do não pagamento das obrigações em investimentos à custa dos fundos trabalhistas que compõem as reservas do banco. ${ }^{13}$

Para operacionalizar a primeira e a segunda rodadas de concessões, que incluíram os aeroportos de São Gonçalo do Amarante (RN), Guarulhos/Cumbica (SP), Viracopos (SP), Brasilia (DF), Galeão (RJ) e Confins (MG), o BNDES disponibilizou linhas de crédito com montantes surpreendentes, mesmo para os padrões das empresas privatizadas da década de 1990, passando, na primeira rodada de concessões, dos $\mathrm{R} \$ 7$ bilhões. Valendo-se do fato de a Infraero ser sócia minoritária, com 49\% de participação na concessão, ficou o banco responsável por disponibilizar até $70 \%$ dos investimentos financiáveis em infraestrutura, definidos segundo as políticas operacionais, podendo alcançar até $90 \%$ dos itens financiáveis a longo prazo, como construções de pistas de pouso, pátios de estacionamento e terminais de passageiros.

12 O PND entrou em vigor em 15 de março de 1990 no início do governo do presidente Collor de Melo e prosseguiu com os governos de Itamar Franco e Fernando Henrique Cardoso.

13 Listamos os principais fundos de recursos do BNDES: Fundo de Amparo ao Trabalhador (FAT); Fundo de Garantia à Exportação (FGE); Programa de Integração Social (PIS); Programa de Patrimônio do Servidor Público (Pasep). 


\section{Tabela 2 - Operações de investimentos do BNDES contratadas pelas con- cessionárias de aeroportos na forma direta e indireta de 2011 a 2017}

\begin{tabular}{|l|l|}
\hline concessionária & investimento (R\$) \\
\hline Concessionária do Aeroporto Internacional de Guarulhos & 4.778 .803 .315 \\
\hline Inframerica Concessionária do Aeroporto de Brasilia S/A & 1.281 .772 .600 \\
\hline Aeroportos Brasil - Viracopos S.A. & 1.241 .676 .722 \\
\hline Inframerica Concessionária do Aeroporto de São Gonçalo & 329.263 .000 \\
\hline total & 7.631 .515 .637 \\
\hline
\end{tabular}

fonte: BNDES (2017). organização e elaboração: Sérgio Teixeira, 2018.

Segundo dados do BNDES, sistematizados na Tabela 2, entre 13 de dezembro de 2012 e 20 de abril de 2015, o banco aprovou empréstimos de longo prazo para os aeroportos de Guarulhos, Brasília, Viracopos e São Gonçalo, num total de R\$ 7,631 bilhões. Os recursos destinaram-se à ampliação, modernização e exploração da infraestrutura dos aeroportos. A concessionária Invepar, responsável pelo aeroporto de Guarulhos, foi contemplada com R\$ 4,778 bilhões. A Inframérica Concessionária, responsável pelo Aeroporto de Brasilia e São Gonçalo, recebeu $\mathrm{R} \$ 1,610$ bilhão.

O que mais surpreende nesses valores é que, segundo o edital do leilão de 02/2011, eles representam grande parte dos investimentos exigidos das concessionárias para ampliação dos aeroportos durante a concessão, pois ao arrematar o aeroporto de Guarulhos a concessionária Invepar, liderada pela megacorporação Airports Company South África Limited, ficou responsável pelo investimento de $\mathrm{R} \$ 4,7$ bilhões em ampliação de infraestrutura. $\bigcirc$ Aeroporto de Brasília (DF), por sua vez, conforme o mesmo edital, deveria receber em investimentos de cerca de $\mathrm{R} \$ 2,85$ bilhões, sendo que metade desse valor era de responsabilidade da concessionária Inframérica, liderada pela EGIS Airport Operation.

A análise desses dados mostra que para a ampliação, manutenção e expansão do Aeroporto Internacional de Guarulhos, a participação dos recursos do BNDES alcançou a totalidade dos investimentos, enquanto no projeto do Aeroporto Internacional de Brasília (DF) esse valor correspondeu a $61 \%$. Dessa maneira, a ampliação dos aeroportos, de responsabilidade das empresas administradoras, acabou sendo garantida em grande parte pelo próprio Estado, por meio dos recuros do BNDES.

Na segunda rodada de concessões a mesma lógica permaneceu. Conforme Decreto Federal 7.896, de 10 de fevereiro de 2013, foram incluídos no PND o Aeroporto Internacional Antônio Carlos Jobim (Galeão), no Rio de Janeiro (RJ), e o Aeroporto Internacional Tancredo Neves (Confins), em Belo Horizonte (MG).

$\mathrm{Na}$ terceira rodada de concessões, em 16/03/2007, por sua vez, foram concedidos o Aeroporto Salgado Filho, em Porto Alegre (RS), o Aeroporto Internacional Deputado Luís Eduardo Magalhaes, em Salvador (BA), o Aeroporto Hercílio Luz, de Florianópolis (SC), e o Aeroporto Pinto Martins, de Fortaleza (CE). Ainda mais corporativa, essa última rodada 
não teve a participação da Infraero como empresa minoritária, mas mesmo assim o BNDES participou provendo $60 \%$ de custeio para investimento em infraestrutura às empresas que arremataram os aeroportos.

Ainda em andamento, as consequências das concessões para o planejamento territorial brasileiro podem também ser apreendidas por meio da análise do controle territorial dos fixos e dos fluxos associados ao planejamento do sistema de aeroportos, como veremos a seguir.

\section{O novo controle da rede aeroportuária}

O controle dos principais aeroportos por grandes corporações confirma o poder estruturador destas no atual planejamento da rede aeroportuária. Organizamos o Mapa 2 para melhor compreender a decorrência da concessão dos aeroportos em questão para a organização territorial da rede de aeroportos administrados pela Infraero. Demonstramos a densidade de passageiros dos 67 aeroportos sob administração da Infraero até 2011 e separamos em destaque os aeroportos que foram concedidos nas três rodadas de concessões referenciados no item anterior.

\section{Mapa 2 - Brasil: número de passageiros embarcados e desembarcados nos aeroportos da Infraero por rodada de concessões (números absolutos)}

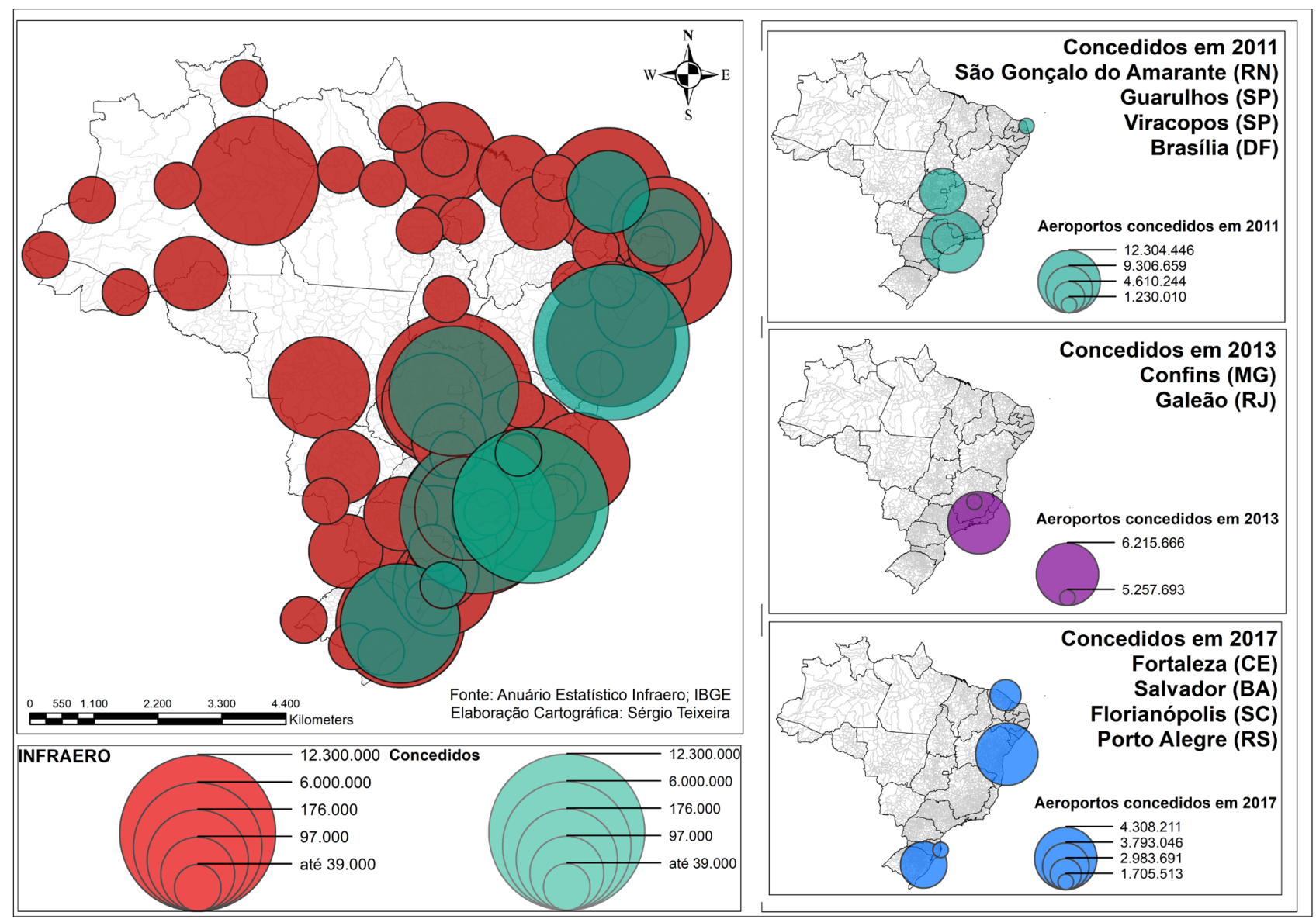

fonte: Infraero (2018); IBGE (2013). elaboração cartográfica: Sérgio Teixeira, 2018. 
Do total dos 94 milhões de embarques e desembarques de passageiros em 2015, 50 milhões foram realizados nos aeroportos concedidos, sendo 27 milhões referentes à primeira rodada de concessões, 11 milhões à segunda rodada e 12 milhões à terceira (Mapa 2). Ou seja, cerca de 53\% dos embarques e desembarques de passageiros estão em poder das corporações que arremataram os aeroportos em questão.

A magnitude do processo de concessão tem como decorrência o controle de inúmeras redes de conexões no território nacional, já que esses voos, como partem da região de maior conectividade, dão acesso a todos os demais aeroportos.

Historicamente os principais fixos aeroportuários convergiram para a Região Concentrada do território e, dessa maneira, os aeroportos situados nessa região acabaram por receber a maior parte das receitas, por consequência são os que operam com lucro. Para manter a rede, os aeroportos não lucrativos vinham recebendo subsídios provenientes dos mais lucrativos, mantendo, assim, a totalidade da rede funcionando. Toda via, tendo esses principais aeroportos agora sob administração privada, os demais passam a ter que receber receitas diretas da União para seu funcionamento, onerando o Estado com custos antes balanceados na própria rede.

Destaca-se a elevada queda nas receitas de carga. Segundo relatório da CGU (2016) e dos Relatórios Anuais da Infraero (Infraero, 2016a), a concessão dos aeroportos de Guarulhos (SP) e Viracopos (SP) representou uma queda de 19\% para 6\% na receita de movimentação de cargas. Se consideradas as receitas totais desvinculadas com a concessão dos aeroportos da primeira rodada de concessões, a Infraero perdeu 34\% de suas receitas e com a segunda rodada $24 \%$. Dos aeroportos rentáveis que permaneceram sob administração da Infraero, quatro entraram na terceira rodada de concessões, todos os quatro aeroportos foram superavitários em 2016 e juntos participaram de 20\% da receita operacional total da Infraero. Com isso, a Infraero passa a operar com menos da metade da receita que tinha antes da concessão.

A perda de receitas, entre outros fatores ${ }^{14}$, fez com que entre 2012 e 2016 a empresa acumulasse um prejuízo que chega ao balanço de patrimônio líquido de $R$ 3,9 bilhões negati$\operatorname{vos}(C G U, 2016)$.

Ao analisar os fluxos de conexão também conseguimos dados importantes sobre o controle territorial das corporações. Separamos no Mapa 3 as principais linhas de ligação, identificando a densidade de fluxo, e em seguida separamos as ligações feitas a partir das cidades nas quais estão instalados os aeroportos concedidos.

14 Entre os demais fatores para o prejuízo anotado no período, nota-se que os aeroportos concedidos não vêm apresentando resultado positivo e a Infraero, além de não receber a contrapartida esperada pela perda da maior parte de suas receitas, ainda absorve parte do prejuízo apurado nas sociedades de propósito específico (SPE), criadas para administrar os aeroportos em que a empresa tem $49 \%$ de participação. 
Mapa 3 - Brasil: fluxo de passageiros nos aeroportos da Infraero por rodada de concessões

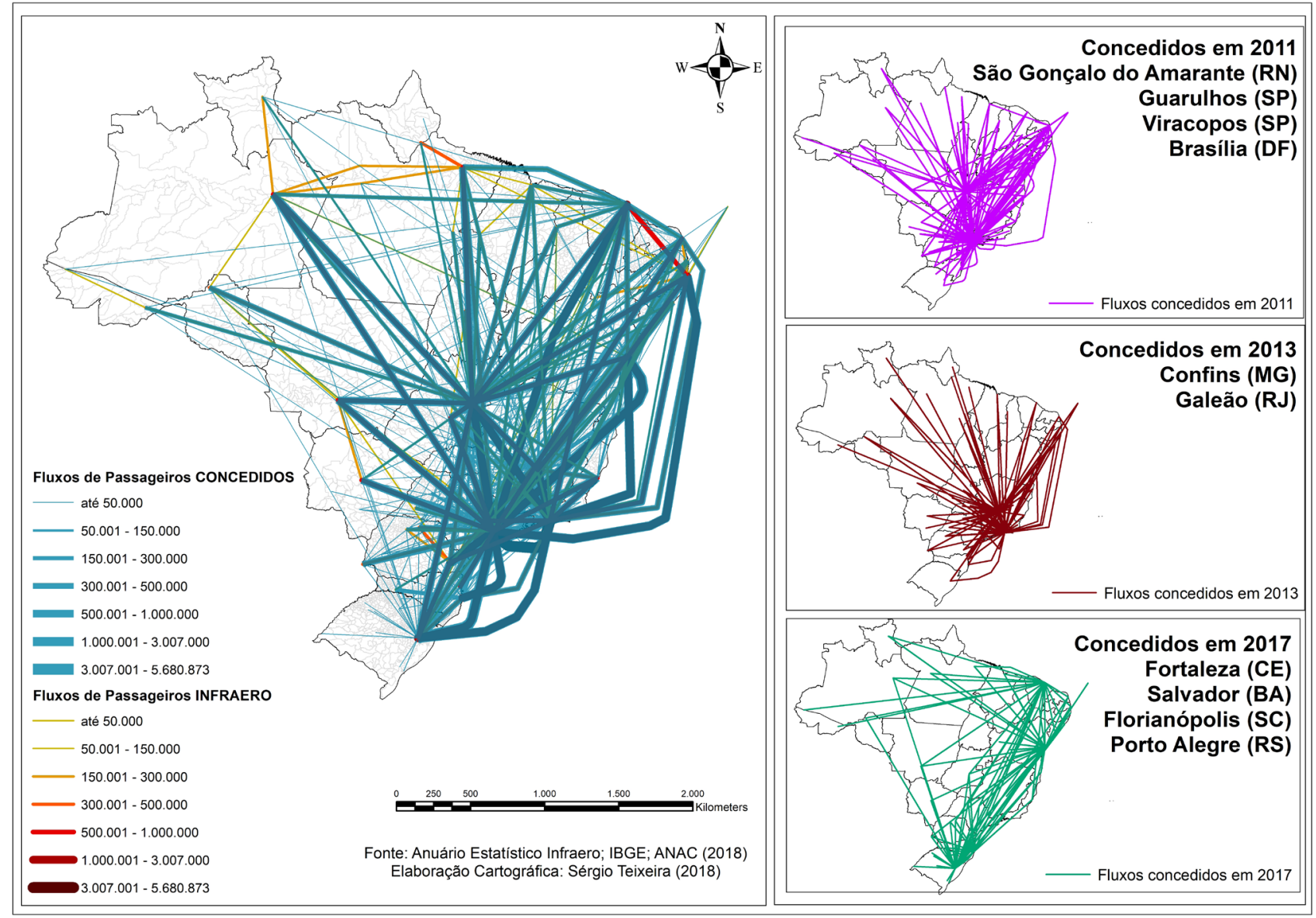

fonte: Infraero (2018); IBGE (2013).

elaboração cartográfica: Sérgio Teixeira, 2018).

Tomamos certo cuidado com os dados, pois as ligações de São Paulo (SP) são referentes aos aeroportos de Guarulhos e Congonhas (este último não concedido) e as ligações que partem do Rio de Janeiro contabilizam além do aeroporto do Galeão, o aeroporto Santos Dumont (este último também não concedido). Isso não prejudica a análise, visto que aproximadamente 75\% das ligações em São Paulo e Rio de Janeiro se fazem nos aeroportos concedidos.

Nota-se que passaram para as empresas privadas os principais fluxos da rede aeroportuária: das 878 principais ligações da rede (72 milhões de passageiros), 372 ligações (64 milhões de passageiros) partem das cidades que tiveram seus aeroportos concedidos. Esses números estão distribuídos entre 157 ligações e 43 milhões de passageiros para a primeira rodada de concessões; 108 ligações e 14 milhões de passageiros para a segunda rodada e 107 ligações com 7 milhões de passageiros para a terceira.

Verifica-se que, por meio desses aeroportos, as corporações apropriam-se das interligações que possibilitam acesso a todo o território a partir da rede mais densa. Destaca-se, ainda, que o padrão concentrador da rede aérea reproduz o padrão de desigualdades internas presentes na rede urbana; mais uma vez a Região Concentrada é a mais privilegiada em termos 
de acessibilidade do modal aéreo no território brasileiro e as regiões Norte e Nordeste as menos favorecidas. Essa herança heterogênea se aprofunda a cada dia, pois a divisão do trabalho também se aprofunda. Essa rede complexa em poder de grandes corporações pode trazer decorrências desastrosas para o território, aprofundando essas assimetrias.

\section{Considerações finais}

A análise da rede aeroportuária do Brasil, estruturada no período técnico-científico-informacional (Santos, 1996), revela que os fluxos se tornaram cada vez mais rápidos, requerendo fixos que aportassem essa rapidez. Foram as mudanças no padrão de circulação no território, com as novas atividades econômicas associadas sobretudo ao desenvolvimento dos serviços informacionais, que provocaram a aceleração do tempo e a necessidade de maior fluidez na movimentação de pessoas e mercadorias.

Os sistemas de engenharia materializados em grandes aeroportos construídos nas décadas de 1950 a 1970 projetaram a possibilidade da maior fluidez no território. Esses aeroportos foram inseridos em meio à divisão territorial e à integração do território pretérita, aprofundando as características das funções de subordinação e controle das diversas regiões do espaço brasileiro, agora cada vez mais fragmentado.

O expressivo crescimento dos fluxos no território destacou a rede de aeroportos brasileiros como centrais na interligação do território e na modernização da rede de cidades, influenciando as hierarquias e os papéis de comando. A importância desse sistema também se dá pelo conteúdo corporativo, afinal, segundo Corrêa (1977, p. 93), “[...] tudo indica que é através das ligações aéreas que as interações de alto nível se realizam: direção e administração de empresas e instituições de alcance espacial que interessam as várias regiões do país".

A densidade dos fluxos aeroportuários concentrados nas regiões Sul e Sudeste nos alerta para as consequências da transferência dos principais aeroportos do Brasil para as corporações. Comandando os maiores aeroportos, localizados nos principais centros de gestão, as corporações passam a ter grande poder de articulação do território nacional.

Por fim, a análise do relatório encomendado pelo BNDES à consultoria McKinsey $\mathcal{E}$ Company revelou que há uma lógica corporativa nos pacotes gerenciais, que, se forem adotados pelo Estado, levam à implementação de medidas que só beneficiam as grandes corporações. Ao mesmo tempo, após realizar os mais diversos estudos e por estarem ligadas às corporações que passam a organizar as infraestruturas territoriais, essas empresas acabam por organizar o planejamento territorial, tornando-o corporativo.

Ao contrário do mito propagado pelos agentes hegemônicos, tributários dos discursos da globalização, sob a insígnia da privatização, o Estado está longe de perder seu protagonismo no planejamento territorial (Santos, 2013; Dardot; Laval, 2016). Outrossim, permanece como ente fundamental para a organização do capitalismo, no que concerne à sua capacidade de extrair recursos públicos e articular as normas que sustentam a organização do território em favor das empresas. ${ }^{15}$

15 "A crise de regulação que o Estado atravessa neste período não se dá em função de uma obsolescência de sua forma e de seu ente; reside, antes, na crença de que ele é o único a regular o território em que está circunscrito. Caso não tivesse seu papel preponderante na regulação social, os investimentos na organização de mediação de conflitos 
Partindo de uma visão atual do processo de acumulação permanente, consideramos que o aprofundamento da divisão territorial do trabalho agora se faz por meio de uma acumulação primitiva em seu caráter de espoliação. Ou seja, a entrada das corporações em novos setores e territórios cumpriria a função de expropriação dos espaços nacionais - por meio de concessões e privatizações - para engendrar oportunidades lucrativas capazes de absorver excedentes de capitais não empregados e desvalorizados em outros territórios. Trata-se de um tema aberto à pesquisa, fundamental para se qualificarem as novas produções e o uso corporativo dos espaços nacionais no período atual.

\section{Referências}

ADVENT INTERNATIONAL. Disponível em: https://www.adventinternational.com/global-reach/. Acesso em: 11 jul. 2019.

ANAC. AGÊNCIA NACIONAL DE AVIAÇÃO CIVIL. Anuário estatístico do transporte aéreo. Estatístico. Brasilia: Anac, 1972-2010. Disponível em https://www.anac. gov.br/assuntos/dados-e-estatisticas/dados-estatisticos/dados-estatisticos. Acesso em: 9 jul. 2019.

ANAC. AGÊNCIA NACIONAL DE AVIAÇÃO. Relatório de desempenho regulatório 2008. Brasília/Rio de Janeiro: Anac, 2008. Disponível em https://www.anac.gov.br/ publicacoes/publicacoes-arquivos/relatorio_de_atividades_anac_2008.pdf. Acesso em: 9 jul. 2019.

ANDRADE GUTIERREZ. Disponível em: http://www.andradegutierrez.com.br/Infraestrutura.aspx. Acesso em: 23 jul. 2019.

ANTAS JR., R. M. Território e regulação: espaço geográfico, fonte material e não formal do direito. São Paulo: Humanitas/Fapesp, 2005.

ANTUNES, R. Os sentidos do trabalho. São Paulo: Boitempo, 1999.

BNDES. BANCO NACIONAL DE DESENVOLVIMENTO ECONÔMICO E SOCIAL. Relatório de Operações contratadas na forma direta e indireta não automática do BNDES. 2017. Disponível em: https://www.bndes.gov.br/wps/portal/site/ home/transparencia/centraldedownloads. Acesso em: 23 jul. 2019.

BNDES. BANCO NACIONAL DE DESENVOLVIMENTO ECONÔMICO E SOCIAL. Programa Nacional de Desestatização. Relatório de Atividades 2015. Brasilia: Ministério do Planejamento, Desenvolvimento e Gestão: Departamento de Comunicação e Difusão de Conhecimento, 2016. Disponível em: https://web.bndes.gov.br/bib/jspui/ bitstream/1408/13334/1/Relatorio\%20PND_2015.pdf. Acesso em 23 jul. 2019.

e de arrecadação de tributos ocorreriam com dificuldade e haveria grande polêmica em torno do desperdício, que habitualmente se propala contra as intervenções estatais" (Antas Jr., 2005, p. 51). 
BNDES. BANCO NACIONAL DE DESENVOLVIMENTO ECONÔMICO E SOCIAL.

Projetos do setor de transporte aéreo e concessão de aeroportos. Rio de Janeiro: BNDES, 2008. Disponível em http://www2.anac.gov.br/arquivos/pdf/apresentacoesAnac/Cleverson_Aroeira___BNDES_[Modo_de_Compatibilidade].pdf. Acesso em: 9 jul. 2019.

CGU. CONTROLADORIA GERAL DA UNIÃO. Relatório de avaliação de resultados de gestão: monitoramento das demonstrações contábeis da Infraero. Avaliação de Resultados. Brasilia, DF, 2016.

CHESNAIS, F. A mundialização do capital. São Paulo: Xamã, 1996.

CONTEL, F. B. Os sistemas de movimento do território brasileiro. In: SANTOS, M; SILVEIRA, M. L. (Ed.). O Brasil: território e sociedade no início do século XXI. São Paulo: Edusp, 2001. p. 357-374.

CORDEIRO, H. K.; LADEIRA F. S. B. O espaço aéreo favorece a desterritorialidade? In: SANTOS, M.; SOUZA, M. A.; SILVEIRA, M. L. (Org.). Território: globalização e fragmentação. São Paulo: Hucitec, 1988. p. 283-295.

CORRÊA, R. L. Estudo sobre a rede urbana. Rio de Janeiro: Bertrand Brasil, 2006.

CORRÊA, R. L. Centros de gestão no território: uma nota. Território, Rio de Janeiro, v. 1, n. 1, p. 23-30, 1996.

CORRÊA, R. L. O sistema urbano brasileiro: uma análise através dos fluxos aéreos de passageiros. Revista Brasileira de Geografia, v. 3, n. 39, p. 92-111, 1977.

DARDOT, P.; LAVAL, C. A nova razão do mundo: ensaio sobre a sociedade neoliberal. Trad. Mariana Echalar. São Paulo: Boitempo, 2016.

DUCLOS, F. Grève à ADP : aucun impact prévu sur les vols. Air Journal, 28 juin 2013. Disponível em: https://www.air-journal.fr/2013-06-28-greve-a-adp-aucun-impact-prevu-sur-les-vols-577509.html. Acesso em: 6 jun. 2018.

FIÚZA, E. P. S.; PIONER, H. M. Estudo econômico sobre regulação e concorrência no setor de aeroportos. Rio de Janeiro: Anac, 2009. Disponível em https://www.anac. gov.br/acesso-a-informacao/biblioteca/arquivos/estudosregulatorios.pdf. Acesso em: 9 jul. 2019.

GROUPE ADP. Disponível em: http://www.parisaeroport.fr/en/homepage-group. Acesso em: 23 jul. 2019.

HARVEY, D. A produção capitalista do espaço. São Paulo: Annablume, 2005.

HARVEY, D. O novo imperialismo. São Paulo: Loyola, 2004.

HARVEY, D. A condição pós-moderna. São Paulo: Loyola, 1992.

IBGE. INSTITUTO BRASILEIRO DE GEOGRAFIA E ESTATÍSTICA. Redes e fluxos no território: gestão do território 2014 - Estudo de fluxos. Rio de Janeiro: IBGE, 2014. 
IBGE. INSTITUTO BRASILEIRO DE GEOGRAFIA E ESTATÍSTICA. Redes e fluxos no território: ligações aéreas 2010. Estudo. Rio de Janeiro: IBGE, 2013. Disponível em https://biblioteca.ibge.gov.br/index.php/biblioteca-catalogo?view=detalhes $\mathcal{E}$ id=287896. Acesso em: $10 \mathrm{dez} .2018$.

IBGE. INSTITUTO BRASILEIRO DE GEOGRAFIA E ESTATÍSTICA. Regiões de influência de cidades. Rio de Janeiro: IBGE, 2008.

INFRAERO. EMPRESA BRASILEIRA DE INFRAESTRUTURA AEROPORTUÁRIA. Anuário estatístico Operacional (2010-2018). Brasilia: Infraero, 2018. Disponível em: https://transparencia.infraero.gov.br/estatisticas/. Acesso em: 10 dez. 2018.

INFRAERO. EMPRESA BRASILEIRA DE INFRAESTRUTURA AEROPORTUÁRIA. Relatório Anual (2012-2016). Brasilia: Infraero, 2016a. Disponível em https://transparencia.infraero.gov.br/relatorios-anuais/. Acesso em: 10 jun. 2018.

INFRAERO. EMPRESA BRASILEIRA DE INFRAESTRUTURA AEROPORTUÁRIA. Balanço administrativo. Administrativo. Brasilia: Infraero, $2016 \mathrm{~b}$.

INVEPAR. Mobilidade Inteligente. Disponível em: http://www.invepar.com.br. Acesso em: 23 jul. 2019.

KAPP, D. C. Aeroportos privatizações: proposta de privatização aeroportuária para o Brasil. Brasilia: Comando da Aeronáutica, Departamento de aviação Civil, 2003.

LOJKINE, J. A revolução informacional. São Paulo: Cortez, 1995.

MCKINSEY \& COMPANY. Forbes, Jersey City, NJ, Oct. 2018. Disponível em: https:// www.forbes.com/companies/mckinsey-company/. Acesso em: 20 dez. 2018.

MCKINSEY \& COMPANY. McKinsey \& Company Global Media Report 2016. London: Global Media and Entertainment Practice, 2016. Disponível em: https://www. mckinsey.com/industries/media-and-entertainment/our-insights/global-media-report-2016. Acesso em: 20 dez. 2018.

MCKINSEY \& COMPANY. Estudo do setor de transporte aéreo do Brasil: relatório consolidado. Rio de Janeiro: McKinsey \& Company, 2010. Disponível em https://web. bndes.gov.br/bib/jspui/handle/1408/7666. Acesso em: 9 jul. 2019.

SANTOS, M. Por uma outra globalização. São Paulo: Record, 2013.

SANTOS, M. Da totalidade ao lugar. São Paulo: Edusp, 2005.

SANTOS, M. Da política dos Estados à política das empresas. Cadernos da Escola do Legislativo de Belo Horizonte, n. 3, p. 9-23, 1998.

SANTOS, M. A natureza do espaço. São Paulo: Hucitec, 1996.

SANTOS, M. O retorno do território. In: SANTOS, M.; SOUZA, M. A.; SILVEIRA, M.

L. (Org.). Território: globalização e fragmentação. São Paulo: Anpur/Hucitec, 1994. p. 15-20.

SANTOS, M. A urbanização brasileira. São Paulo: Hucitec, 1993. 
SANTOS, M. Metrópole corporativa e fragmentada: o caso de São Paulo. São Paulo: Nobel, 1990.

SANTOS, M. Society and space: social formation as theory and method. Antipode, v. 9, n. 1, p. 3-13, fev. 1977.

SANTOS, M.; SILVEIRA, M. L. O Brasil: território e sociedade no século XXI. Rio de Janeiro: Record, 2001.

SILVA, A. M. B. Círculos globais de informações e uso corporativo do território brasileiro: privatizações e planejamento territorial a partir dos anos 1990. Cadernos IPPUR/UFRJ, v. XXIII, p. 9-32, 2009.

SILVA, A. M. B. São Paulo, produção de informações e novo uso do território brasileiro. Tese (Doutorado em Geografia) - Faculdade de Filosofia, Letras e Ciências Humanas, Universidade de São Paulo, São Paulo, 2002.

SILVA, A. M. B. A nova divisão territorial do trabalho brasileira e a produção de informações na cidade de São Paulo (as empresas de consultoria). In: SANTOS, M.; SILVEIRA, M. L. O Brasil. Território e Sociedade no início do século XXI. Rio de Janeiro: Record, 2001. p. 413-432.

SILVA, A. M. B.; FARIAS, H. C. O BNDES e as empresas de consultoria na reorganização do território brasileiro na década de 1990. Redes, Santa Cruz do Sul, v. 13, p. 99-120, 2008.

SILVA, A. M. B.; MANZONI NETO, A. O planejamento territorial no Brasil nos anos 1990: as ações das empresas globais de consultoria (o caso da empresa Booz-Allen E Hamilton). GEOgraphia, Niterói: UFF, v. 10, p. 1-23, 2008.

TEIXEIRA, S. H. O. Planejamento corporativo e concessão aeroportuária no Brasil. Mercator, Fortaleza, v. 17, p. 1-15, 2018a.

TEIXEIRA, S. H. O. Planejamento, informação e circulação: as concessões dos aeroportos brasileiros e os usos corporativos do território. Tese (Doutorado em Geografia) - Instituto de Geociências, Universidade Estadual de Campinas, Campinas, 2018b.

TEIXEIRA, S. H. O.; SILVA, A. M. B. Os usos da informação estratégica sobre o território: A empresa de consultoria Price Water House Coopers e o Planejamento Territorial. Revista Brasileira de Estudos Urbanos e Regionais, Rio de Janeiro, v. 13, p. 71-86, 2011.

VAINER, C. B. Planejamento territorial e projeto nacional. Revista Brasileira de Estudos Urbanos e Regionais, Rio de Janeiro, v. 9, n. 1, p. 9-23, 2007. 